Review Article

\title{
A Review on the Synthesis of Manganese Oxide Nanomaterials and Their Applications on Lithium-Ion Batteries
}

\author{
Xiaodi Liu, Changzhong Chen, Yiyang Zhao, and Bin Jia \\ College of Chemistry and Pharmaceutical Engineering, Nanyang Normal University, Nanyang, Henan 473061, China \\ Correspondence should be addressed to Xiaodi Liu; liuxd1983@yahoo.com.cn
}

Received 21 January 2013; Accepted 22 February 2013

Academic Editor: Bo Yu

Copyright (C) 2013 Xiaodi Liu et al. This is an open access article distributed under the Creative Commons Attribution License, which permits unrestricted use, distribution, and reproduction in any medium, provided the original work is properly cited.

\begin{abstract}
Most recently, manganese oxides nanomaterials, including $\mathrm{MnO}$ and $\mathrm{MnO}_{2}$, have attracted great interest as anode materials in lithium-ion batteries (LIBs) for their high theoretical capacity, environmental benignity, low cost, and special properties. Up to now, manganese oxides nanostructures with excellent properties and various morphologies have been successfully synthesized. Herein, we provide an in-depth discussion of recent development of the synthesis of manganese oxides nanomaterials and their application in the field of LIBs.
\end{abstract}

\section{Introduction}

Nanomaterials, having a length scale less than $100 \mathrm{~nm}$, have received increasing interest owing not only to their fundamental scientific significance but also to the potential applications that derive from their fascinating electrical, magnetic, and catalytic properties [1]. Compared to bulk active electrode materials, the corresponding nanomaterials possess more excellent electrochemical activity, such as higher capacities, larger surface areas, and lower current densities, thereby, nanomaterials have wildly potential application in electrochemistry field. Manganese oxides, including $\mathrm{MnO}, \mathrm{MnO}_{2}$, and $\mathrm{Mn}_{3} \mathrm{O}_{4}$, are intriguing composites and have been used in wastewater treatment, catalysis, sensors, supercapacitors, and alkaline and rechargeable batteries [2-6]. Particularly, $\mathrm{MnO}$ and $\mathrm{MnO}_{2}$ nanomaterials have attracted great interest as anode materials in lithium-ion batteries (LIBs) for their high theoretical capacity, low cost, environmental benignity, and special properties [7-9].

It is known that the phases, sizes, and morphologies of nanomaterials have great influence on the properties and applications; therefore, many research efforts have focused on rational control of phase, shape, size, and dimensionality of nanomaterials [14]. Several novel and effective routes have been devoted to prepare manganese oxides nanomaterials with various shapes and excellent properties, such as hydrothermal method [15-18], sol-gel synthesis [19], wet chemical route $[12,20,21]$, pulsed laser deposition method [22], and precursor technique [23]. Moreover, lots of successes on the properties and applications of manganese oxides nanomaterials have been reported in the last few years, for example, a hydrothermal method has been used to synthesize sea urchin shaped $\alpha-\mathrm{MnO}_{2}$ [24]; Wu et al. have prepared $\gamma-\mathrm{MnO}_{2}$ hexagon-based layer-cake-like and intertexture-like nanoarchitectures via a hydrothermal route [25]; Liu and coworkers have found $\mathrm{MnO}_{2}$ nanoparticleenriched poly(3,4-ethylenedioxythiophene) nanowires that could maintain high specific capacitance at high chargedischarge rates [26]. Thus, it is necessary to review the development of manganese oxides nanomaterials to keep the readers abreast of the rapid development. In this paper, we review the synthesis of manganese oxides nanomaterials with various morphologies and their application on LIBs; furthermore, the future prospects have also been discussed.

\section{Synthesis of Manganese Oxide Nanomaterials}

2.1. Synthesis of $\mathrm{MnO}_{2}$ Nanomaterials. It is known that $\mathrm{MnO}_{2}$ can exist in different structural forms, $\alpha-, \beta-, \gamma-, \delta$-, $\varepsilon$ and $\lambda$-types and so forth, when the basic structural unit $\left(\left[\mathrm{MnO}_{6}\right]\right.$ octahedron) is linked in different ways. Based on the different $\left[\mathrm{MnO}_{6}\right]$ links, $\mathrm{MnO}_{2}$ can be divided into three 


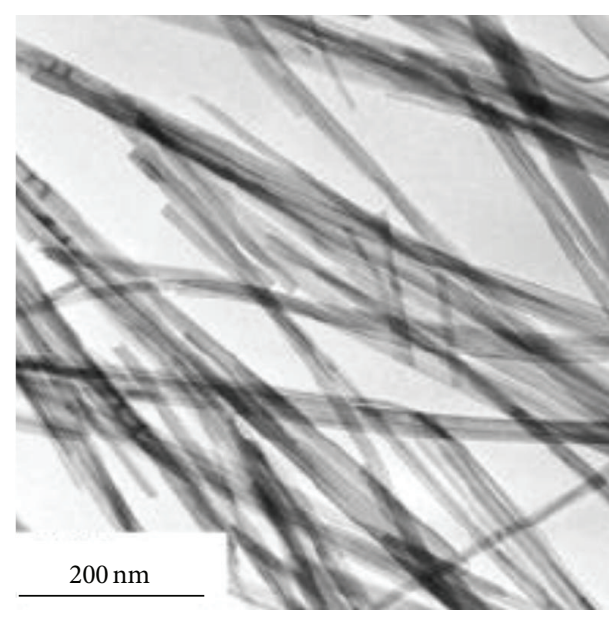

(a)

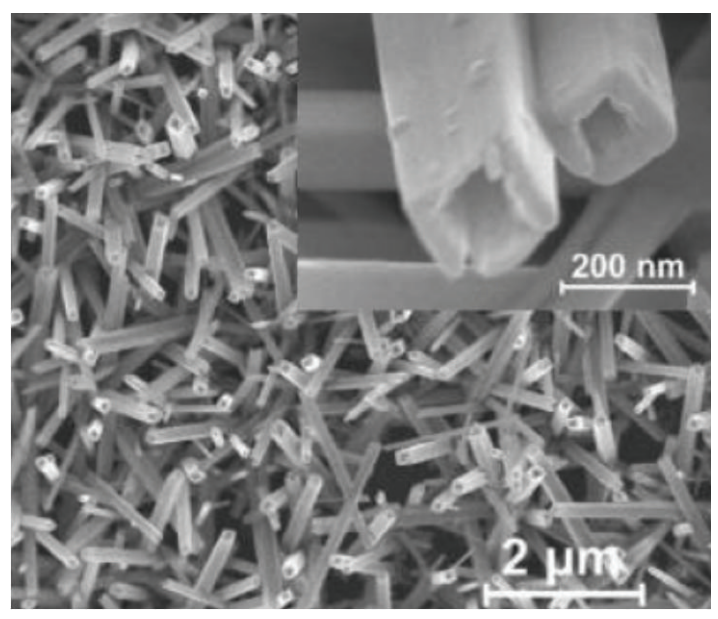

(b)

Figure 1: (a) TEM image of $\alpha-\mathrm{MnO}_{2}$ nanowires and (b) SEM image of $\alpha-\mathrm{MnO}_{2}$ nanotubes [10, 11].

categories: the chain-like tunnel structure such as $\alpha$-, $\beta$-, and $\gamma$-types, the sheet or layered structure such as $\delta-\mathrm{MnO}_{2}$, and the $3 \mathrm{D}$ structure such as $\lambda$-type [27]. The properties of $\mathrm{MnO}_{2}$ are significantly affected by their phases and morphologies; moreover, the operating properties of LIBs also depend on the phase of $\mathrm{MnO}_{2}$. In this regard, a great effort has been directed toward the preparation of $\mathrm{MnO}_{2}$ with different phases and various shapes [28]. Generally, $\mathrm{MnO}_{2}$ nanostructures could be synthesized through the oxidation of $\mathrm{Mn}^{2+}$, reduction of $\mathrm{MnO}_{4}{ }^{-}$, redox reactions between $\mathrm{Mn}^{2+}$ and $\mathrm{MnO}_{4}{ }^{-}$, or direct phase transformation from other manganese oxides.

$1 \mathrm{D} \mathrm{MnO}_{2}$ may provide the possibility of detecting the theoretical operating limits of LIBs, so various $1 \mathrm{D} \mathrm{MnO}_{2}$ nanomaterials have been synthesized $[29,30]$. Chen et al. have synthesized $\mathrm{MnO}_{2}$ with different crystal structures $(\alpha-, \gamma-)$ and morphologies via quick precipitation of $\mathrm{Mn}^{2+}$ and $\mathrm{Mn}^{7+}$ in water isopropanol without using templates or surfactants [31]. In a typical synthesis, $\mathrm{MnCl}_{2}(0.18 \mathrm{~g})$ mixed with isopropanol $(50 \mathrm{~mL})$ was heated to $83^{\circ} \mathrm{C}$ in a refluxing process, and then $\mathrm{KMnO}_{4}(0.10 \mathrm{~g})$ dissolved in DI water $(5 \mathrm{~mL})$ was added to the solution. Finally, $\mathrm{MnO}_{2}$ nanoneedles were obtained. Singly-crystal nanowires of $\alpha$ - and $\beta-\mathrm{MnO}_{2}$ have been prepared in a hydrothermal procedures employing $\mathrm{Mn}^{2+}$ with oxidizing reagents such as $\left(\mathrm{NH}_{4}\right)_{2} \mathrm{~S}_{2} \mathrm{O}_{8}$ or $\mathrm{KMnO}_{4}$ $[28,32]$. Ma group have used a hydrothermal method for $\mathrm{MnO}_{2}$ nanobelts, which have narrow size dispersions and can be self-assembled into bundles [6]. In a typical procedure, $\mathrm{Mn}_{2} \mathrm{O}_{3}$ powders $(2 \mathrm{~g})$ were dispersed in $\mathrm{NaOH}$ aqueous solution $\left(10 \mathrm{~mol} \cdot \mathrm{dm}^{-3}\right)$, and then the solution was sealed and heated at $170^{\circ} \mathrm{C}$ for $12 \mathrm{~h}$ to 1 week. Sui et al. have synthesized $\alpha-\mathrm{MnO}_{2}$ nanowires and $\beta-\mathrm{MnO}_{2}$ nanorods via molten salt method [10]. In the synthesis, $\mathrm{KNO}_{3}, \mathrm{NaNO}_{3}$, and $\mathrm{LiNO}_{3}$ are applied as the reaction media. $\alpha-\mathrm{MnO}_{2}$ is a $(2 \times 2)$ and $(1 \times 1)$ tunnel structure, and large ions $\left(\mathrm{K}^{+}\right)$are needed to support the framework; thus, $\mathrm{KNO}_{3}$ is used as molten salt to prepare $\alpha-\mathrm{MnO}_{2}$ nanomaterials (Figure $1(\mathrm{a})$ ). $\beta-\mathrm{MnO}_{2}$ is a $(1 \times 1)$ tunnel structure, so a mixture of $\mathrm{NaNO}_{3}$ and
$\mathrm{LiNO}_{3}$ with smaller cation is selected. Zheng et al. have prepared $\beta-\mathrm{MnO}_{2}$ nanotubes using $\mathrm{MnSO}_{4}$ as reagent, $\mathrm{PVP}$ as morphology directing agent and $\mathrm{NaClO}_{3}$ as oxidant [33]. $\alpha-\mathrm{MnO}_{2}$ nanotubes have been synthesized by a hydrothermal treatment of $\mathrm{KMnO}_{4}$ in $\mathrm{HCl}$ solution [11]. As shown in Figure 1(b), the obtained nanotubes have an average outer diameter of $100 \mathrm{~nm}$ and the wall thickness of $30 \mathrm{~nm}$, and the length is up to several microns. It is found that the nanotubes are formed via solid nanorods involving in chemical etching process.

Other special shapes, such as nanowalls [34], nanodisks [35], urchin-like nanoballs [27], multipods [36], and nanosheets [37], have been fabricated. Some successes discussed above can be summarized in Table 1 .

Compared to $1 \mathrm{D} / 2 \mathrm{D}$ nanostructures, $3 \mathrm{D} \mathrm{MnO}_{2}$ hierarchical structures often produce more active sites or possess more interesting properties, so great interests have been given to well-defined $\mathrm{MnO}_{2}$ architectures with controlled crystal structures [38]. Six-branched $\varepsilon-\mathrm{MnO}_{2}$ architectures have been synthesized via an aqueous chemical route without any organic templates (Figure 2(a)). The growth rate along the six-fold $c$-axis is faster than along the other axes for the crystal structure of $\varepsilon-\mathrm{MnO}_{2}$, which results in the elongated twinned pyramidal shape of the crystals. Consequently, the edges of the adjacent facets of the pyramid become the nucleation sites, and the sprouted branches form the central core [13]. Jana et al. have used a green method for the synthesis of hierarchical flower-like $\mathrm{Ag}$-doped $\beta-\mathrm{MnO}_{2}$ nanostructures at $300 \mathrm{~K}$. As displayed in Figure 2(b), the flowery nanostructures are composed of tiny nanopetals $(500 \mathrm{~nm}$ in diameter and $1.25 \mu \mathrm{m}$ in length) [12]. Fei group have reported a controlled synthesis of hollow microspheres and microcubes of hierarchical $\mathrm{MnO}_{2}$ superstructures using $\mathrm{MnCO}_{3}$ crystals as the templates [39]. $\mathrm{MnCO}_{3}$ microspheres and microcubes are synthesized by the reaction of $\mathrm{MnSO}_{4}$ and $\mathrm{NH}_{4} \mathrm{HCO}_{3}$, and $\mathrm{MnO}_{2}$ hollow microspheres and microcubes are prepared by mixing $\mathrm{KMnO}_{4}$ and the solid $\mathrm{MnCO}_{3}$ crystals. In 
TABle 1: Synthesis of $\mathrm{MnO}_{2}$ with different morphologies.

\begin{tabular}{|c|c|c|c|}
\hline Method & Morphology & Size & Year \\
\hline Molten salt route & $\begin{array}{l}\text { Nanowires } \\
\text { Nanorods }\end{array}$ & $\begin{array}{l}\text { Length of several microns and diameter of } 15-30 \mathrm{~nm} \\
\text { Length of } 500 \mathrm{~nm}-2 \mu \mathrm{m} \text { and diameter of } 20-40 \mathrm{~nm}\end{array}$ & $2009[10]$ \\
\hline Hydrothermal method & $\begin{array}{l}\text { Urchin-like } \\
\text { nanoballs }\end{array}$ & Diameter of $1 \mu \mathrm{m}$ & 2010 [27] \\
\hline Microemulsion method & Nanodisks & Size of $1-2 \mu \mathrm{m}$ and thickness of $50-100 \mathrm{~nm}$ & 2007 [35] \\
\hline Hydrothermal method & Nanotubes & Outer diameter of $100 \mathrm{~nm}$, wall thickness of $30 \mathrm{~nm}$, and length of several microns & 2008 [11] \\
\hline Hydrothermal method & Multipods & The legs of the multipods are $200-600 \mathrm{~nm}$ in width and several microns in length & 2006 [36] \\
\hline
\end{tabular}

the synthesis, a microscale Kirkendall effect is used for the synthesis of hollow microstructures. Other hierarchical architectures with novel morphologies have also been prepared [20, 40-44], such as $\lambda-\mathrm{MnO}_{2}$ nanodisks assembled from nanoparticles via a novel wet chemical route [20] and $\mathrm{MnO}_{2}$ microspheres composed of nanodisks [41].

2.2. Synthesis of $\mathrm{MnO}$ Nanomaterials. $\mathrm{MnO}$, a simple binary metal oxide, has an Fm-3m rock-salt structure with a lattice constant of $4.445 \AA$ at $300 \mathrm{~K}$ and has attracted strong interest for its application as catalysts [45], contrast enhancement for magnetic resonance imaging (MRI) [46], and LIBs materials [47]. Currently, several methods have been developed for the fabrication of $\mathrm{MnO}$ nanostructures with well-controlled shapes, such as nanocrystals [48], nanofibers [49], and nanosheets [50]. Monodisperse MnO nanocrystals have been synthesized by thermal decomposition of manganese oleate using the hot-injection method or thermal decomposition of manganese acetate in the presence of oleic acid [51,52]. Park et al. have prepared $\mathrm{MnO}$ nanospheres (sizes of 5-40 nm) and nanorods (diameters of 7-10 $\mathrm{nm}$ and lengths of 30-140 nm) by the thermal decomposition of Mn-surfactant complexes [53]. Nanoscale $\mathrm{MnO}$ octahedrons have been prepared by decomposing manganese oleate in octadecene and $\mathrm{S}$ at high temperature [54]. Xie and coworkers have fabricated supercrystals (SCs) assembled of octahedral $\mathrm{MnO}$ nanocrystals (NCs) [55]. In the synthesis, octahedral $\mathrm{MnO} \mathrm{NCs}$ are synthesized by thermal deposition of $\mathrm{Mn}\left(\mathrm{OOC}_{2} \mathrm{H}_{5}\right)_{2}$ assisted by a mixed solvent of TOA and OA, and then microscale cubic SCs built by NCs are created via direct crystallization in ethanol (Figures 3(a) and 3(b)). Other unusual shapes, such as nanoclusters, nanocube, and nanoflake, have also been fabricated [56-59]. Besides rock-salt structure, $\mathrm{MnO}$ has another crystal structure, which is hexagonal wurtzite. $\mathrm{Nam}$ et al. have reported the synthesis of wurtzite $\mathrm{MnO}$ on a carbon template, which may offer an extra degree of freedom in the design of sensors and energy storage devices (Figure 3(c)) [60, 61].

Hybrid nanostructures consisting of two or more different functional units possess novel and enriched properties for magnetic, optical, and catalytic applications. As to $\mathrm{MnO}$, several hybrid nanomaterials have been fabricated, such as porous $\mathrm{C}-\mathrm{MnO}$ disks, $\mathrm{MnO} / \mathrm{C}$ nanotubes, $\mathrm{MnO} / \mathrm{SiO}_{2}$ core-shell nanoparticles, and $\mathrm{MnO} / \mathrm{C}$ core-shell nanoplates $[16,62-64]$.

\section{Applications of Manganese Oxide Nanomaterials on Lithium-Ion Batteries (LIBs)}

Lithium-ion batteries (LIBs) are regarded as a promising rechargeable power sources for hybrid electric vehicles (HEVs) and portable electronic devices for their high specific capacity, long cycle life, and lack of memory [65]. Electrode materials play an important role in the performance of LIBs. It was found that transition metal oxides nanomaterials are very appealing anode materials owing to their higher theoretical capacities than that of commercial graphite (372 $\mathrm{mA} \cdot \mathrm{h}^{-\mathrm{g}^{-1}}$ ) [66]. Among them, nanoscales $\mathrm{MnO}$ and $\mathrm{MnO}_{2}$ have attracted more and more attention due to the high theoretical capacities, environmentally benign, low cost, and special properties.

Zhao et al. have synthesized nanoporous $\gamma-\mathrm{MnO}_{2}$ hollow microspheres and nanocubes with high initial capacities and excellent cycle performance in LIBs. The $\gamma-\mathrm{MnO}_{2}$ architectures provide more possibility to serve as an ideal host material for the insertion and extraction of lithium ions for the nanoporous structure. After 20 cycles, the capacities of the $\gamma-\mathrm{MnO}_{2}$ microspheres and nanocubes are 602.1 and $656.5 \mathrm{~mA} \cdot \mathrm{h} \cdot \mathrm{g}^{-1}$ [67]. Interconnected porous $\mathrm{MnO}$ nanoflakes have been prepared on $\mathrm{Ni}$ foam. The obtained nanoflakes retain a capacity of $708.4 \mathrm{~mA} \cdot \mathrm{h} \cdot \mathrm{g}^{-1}$ at the 200 th chargedischarge cycle after cycling with different current densities up to $2460 \mathrm{~mA} \cdot \mathrm{g}^{-1}$ and deliver a capacity of $376.4 \mathrm{~mA} \cdot \mathrm{h} \cdot \mathrm{g}^{-1}$ at $2460 \mathrm{~mA} \cdot \mathrm{g}^{-1}$. The special morphology of the porous $\mathrm{MnO}$ nanoflake affected its electrochemical property: (I) the nanomaterials have a large specific area and offer a large material/electrolyte contact area; (II) the structure can supply enough space to buffer the volume change caused by the electrochemical reaction; (III) the nanosize of flakes leads to a shortened electronic and ionic transport length [59]. In addition, Chen et al. have reported the best cycle performance of $\mathrm{MnO}$ anode material, which deliver a capacity of $650 \mathrm{~mA} \cdot \mathrm{h} \cdot \mathrm{g}^{-1}$ after 150 cycles at $35.5 \mathrm{~mA} \cdot \mathrm{g}^{-1}$ [68].

Despite the above successes, there are still many challenges in using $\mathrm{MnO}_{2}$ and $\mathrm{MnO}$ as anode materials for LIBs, such as poor cycling performance and poor electrical conductivity. It has been demonstrated that electrode materials with a deliberately designed nanostructure can partly accommodate the strains of $\mathrm{Li}^{+}$intercalation and deintercalation [62]. The electrical conductivity of manganese oxide can be enhanced by mixing them with electrolytes 


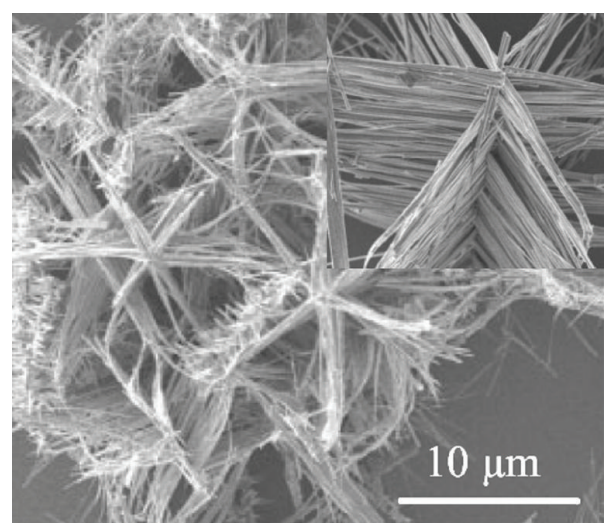

(a)

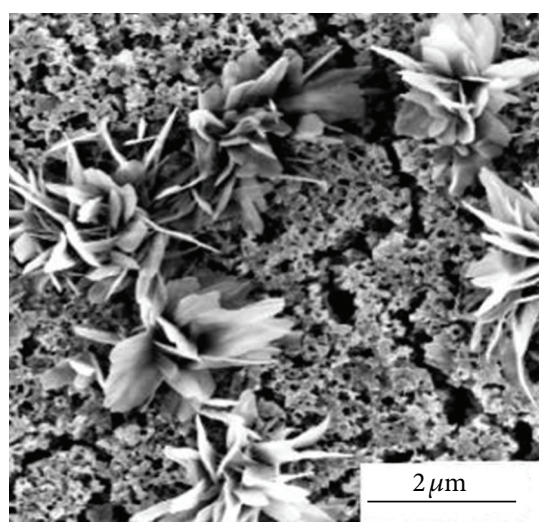

(b)

FIGURE 2: (a) SEM image of hierarchical $\varepsilon-\mathrm{MnO}_{2}$ architectures, the inset is high-magnification SEM image of one architecture, and (b) SEM image of hierarchical flower-like Ag-doped $\mathrm{MnO}_{2}$ nanostructures $[12,13]$.

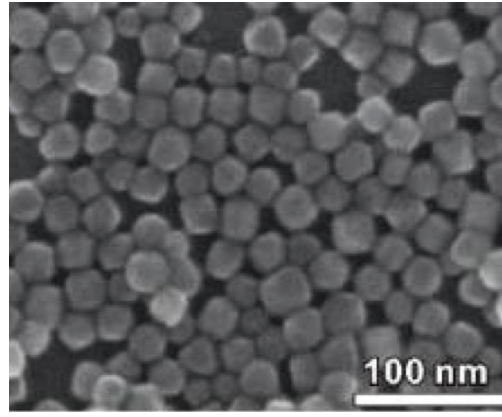

(a)

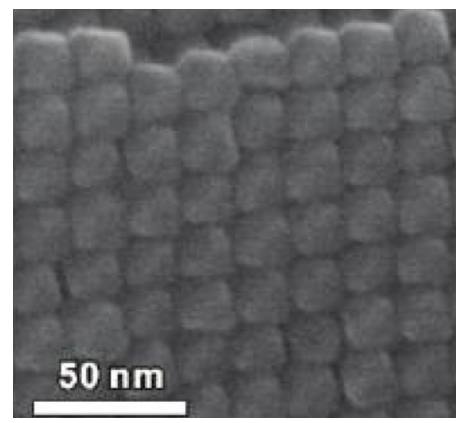

(b)

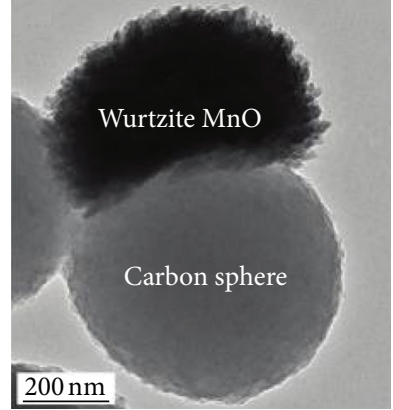

(c)

FIGURE 3: (a) SEM image of disperse MnO octahedral NCs, (b) SEM image of well-oriented MnO SCs, and (c) TEM image of hexagonal wurtzite $\mathrm{MnO}$ on the carbon sphere template $[55,61]$.

[69]. For instance, amorphous $\mathrm{MnO}_{2}$ in a mild $\mathrm{KCl}$ aqueous electrolyte has been proved to be an excellent electrode for the faradaic electrochemical capacitor [70]. More importantly, a common strategy for improving the poor electrical conductivity is combining them with carbon to form composites. After Raymundo-Piñero et al. have studied the electrical conductivity and the capacity of the manganese oxide/C nanotubes composites for the first time, several groups have researched the electrical conductivity of different $\mathrm{MnO} / \mathrm{C}$ composites [71]. For example, $\mathrm{MnO} / \mathrm{C}$ core-shell nanoplates with a C-shell thickness of about $8.1 \mathrm{~nm}$ display a high reversible capacity of $770 \mathrm{~mA} \cdot \mathrm{h} \cdot \mathrm{g}^{-1}$ at $200 \mathrm{~mA} \cdot \mathrm{g}^{-1}$ [60]. C$\mathrm{MnO}$ disks exhibit a capacity of $534.6 \mathrm{~mA} \cdot \mathrm{h} \cdot \mathrm{g}^{-1}$ after 250 cycles at a relatively high current density of $1000 \mathrm{~mA} \cdot \mathrm{g}^{-1}$. The high capacity and excellent cycling stability can be attributed to the assembled nanoarchitecture including 3D interconnected nanopores, carbon modification, and the small particle sizes of $\mathrm{MnO}$ nanocrystals [64]. Porous $\mathrm{MnO} / \mathrm{C}$ nanotubes can deliver a reversible capacity as high as $763.3 \mathrm{~mA} \cdot \mathrm{h} \cdot \mathrm{g}^{-1}$ after 100 cycles at a charge/discharge current density of $100 \mathrm{~mA} \cdot \mathrm{g}^{-1}$. The superior cyclability and rate capability are attributed to the hollow interior, porous structure, 1D structure, and the uniformly dispersed carbon in the porous $\mathrm{MnO} / \mathrm{C}$ nanotubes [16]. $\mathrm{MnO} / \mathrm{C}$ nanoparticles have a reversible capacity of $470 \mathrm{~mA} \cdot \mathrm{h} \cdot \mathrm{g}^{-1}$ after the 50 th cycle, when tested at $75 \mathrm{~mA} \cdot \mathrm{g}^{-1}$ [72]. Additionally, it has been found that nanopainting metal oxides with a thin layer of conducting polymers can improve their lithium storage capabilities. Xiao et al. have synthesized porous spheres assembled from polythiophene-coated $\mathrm{MnO}_{2}$ nanosheets. The electrochemical measurements show that the obtained nanocomposites can deliver a capacity of $500 \mathrm{~mA} \cdot \mathrm{h} \cdot \mathrm{g}^{-1}$ after 100 cycles at a current density of $500 \mathrm{~mA} \cdot \mathrm{g}^{-1}$. The high-rate lithium storage capability of the nanocomposites might be explained by the special structure: (I) the ultrathin nanosheets entail a high effective electrolyte/electrode contact area and a short solid-state diffusion length of $\mathrm{Li}^{+}$ions; (II) the mesopores enable fast ionic transport throughout the electrode; (III) the hierarchical structure is beneficial for the stability of the electrode; (IV) the polythiophene "nanopaint" not only enhances the electrical conductivity but also acts as a buffer 
layer for the large volume change and drastic structural or textural alterations during charge/discharge cycling [73].

\section{Conclusions}

In summary, we have briefly reviewed the recent development of manganese oxide nanomaterials. In the near future, we will face some challenges in spite of the successes discussed above. For instance (I) manganese oxide nanomaterials have recently been synthesized in the labs, and they should be applied in industry. Therefore, we should explore simple and effective methods for the synthesis of manganese oxide nanomaterials with high surface areas and good dispersity, and (II) the application of manganese oxide in the field of electrochemistry is still in its infancy; moreover, some data and conclusions are controversial. Thus, the electrochemical mechanism of manganese oxide nanomaterials should be deeply understood. In short, we hope that this paper will not only show the development of manganese oxide nanomaterials but also give the readers some inspiration to explore novel routes for the synthesis of manganese oxide nanomaterials.

\section{Acknowledgments}

This work is financially supported by the Natural Science Foundation of Henan Department of Science \& Technology (no. 112300410224), Natural Science Foundation of Henan Department of Education (no. 13A150813) and the Natural Science Foundation of Nanyang Normal University (no. 2X2010014).

\section{References}

[1] C. Burda, X. B. Chen, R. Narayanan, and M. A. El-Sayed, "Chemistry and properties of nanocrystals of different shapes," Chemical Reviews, vol. 105, no. 4, pp. 1025-1102, 2005.

[2] J. Cao, Q. H. Mao, L. Shi, and Y. T. Qian, "Fabrication of $\gamma-\mathrm{MnO}_{2} / \alpha-\mathrm{MnO}_{2} /$ hollow core/shell structures and their application to water treatment," Journal of Materials Chemistry, vol. 21, pp. 16210-16215, 2011.

[3] D. Yan, S. Cheng, R. F. Zhuo et al., "Nanoparticles and 3D sponge-like porous networks of manganese oxides and their microwave absorption properties," Nanotechnology, vol. 20, no. 10, Article ID 105706, 2009.

[4] Y. W. Tan, L. R. Meng, Q. Peng, and Y. D. Li, "One-dimensional single-crystalline $\mathrm{Mn}_{3} \mathrm{O}_{4}$ nanostructures with tunable length and magnetic properties of $\mathrm{Mn}_{3} \mathrm{O}_{4}$ nanowires," Chemical Communications, vol. 47, no. 4, pp. 1172-1174, 2011.

[5] X. Zhang, Z. Xing, Y. Yu et al., "Synthesis of $\mathrm{Mn}_{3} \mathrm{O}_{4}$ nanowires and their transformation to $\mathrm{LiMn}_{2} \mathrm{O}_{4}$ polyhedrons, application of $\mathrm{LiMn}_{2} \mathrm{O}_{4}$ as a cathode in a lithium-ion battery," CrystEngComm, vol. 14, no. 4, pp. 1485-1489, 2012.

[6] R. Ma, Y. Bando, L. Zhang, and T. Sasaki, "Layered $\mathrm{MnO}_{2}$ nanobelts: hydrothermal synthesis and electrochemical measurement," Advanced Materials, vol. 16, no. 11, pp. 918-922, 2004.

[7] F. Y. Cheng, J. Z. Zhao, W. Song et al., "Facile controlled synthesis of $\mathrm{MnO}_{2}$ nanostructures of novel shapes and their application in batteries," Inorganic Chemistry, vol. 45, no. 5, pp. 2038-2044, 2006.
[8] F. Y. Cheng, J. A. Shen, B. Peng, Y. D. Pan, Z. L. Tao, and J. Chen, "Rapid room-temperature synthesis of nanocrystalline spinels as oxygen reduction and evolution electrocatalysts," Nature Chemistry, vol. 3, pp. 79-84, 2011.

[9] B. Sun, Z. X. Chen, H. S. Kim, H. Ahn, and G. X. Wang, "MnO/C core-shell nanorods as high capacity anode materials for lithium-ion batteries," Journal of Power Sources, vol. 196, no. 6, pp. 3346-3349, 2011.

[10] N. Sui, Y. Duan, X. Jiao, and D. Chen, "Large-scale preparation and catalytic properties of one-dimensional $\alpha / \beta-\mathrm{mno}_{2}$ nanostructures," Journal of Physical Chemistry C, vol. 113, no. 20, pp. 8560-8565, 2009.

[11] J. Luo, H. T. Zhu, H. M. Fan et al., "Synthesis of single-crystal tetragonal $\alpha-\mathrm{MnO}_{2}$ nanotubes," Journal of Physical Chemistry $C$, vol. 112, no. 33, pp. 12594-12598, 2008.

[12] S. Jana, S. Pande, A. K. Sinha et al., "A green chemistry approach for the synthesis of flower-like Ag-doped $\mathrm{MnO}_{2}$ nanostructures probed by surface-enhanced raman spectroscopy," Journal of Physical Chemistry C, vol. 113, no. 4, pp. 1386-1392, 2009.

[13] Y. S. Ding, X. F. Shen, S. Gomez, H. Luo, M. Aindow, and S. L. Sui, "Hydrothermal growth of manganese dioxide into three-dimensional hierarchical nanoarchitectures," Advanced Functional Materials, vol. 16, no. 4, pp. 549-555, 2006.

[14] C. N. R. Rao, S. R. C. Vivekchand, K. Biswas, and A. Govindaraja, "Synthesis of inorganic nanomaterials," Dalton Transactions, no. 34, pp. 3728-3749, 2007.

[15] W. Xiao, D. Wang, and X. W. Lou, "Shape-controlled synthesis of $\mathrm{MnO}_{2}$ nanostructures with enhanced electrocatalytic activity for oxygen reduction," The Journal of Physical Chemistry C, vol. 114, pp. 1694-1700, 2010.

[16] G. L. Xu, Y. F. Xu, H. Sun et al., "Facile synthesis of porous $\mathrm{MnO} / \mathrm{C}$ nanotubes as a high capacity anode material for lithium ion batteries ", Chemical Communications, vol. 48, pp. 85028504, 2012.

[17] D. Yan, P. X. Yan, G. H. Yue et al., "Self-assembled flowerlike hierarchical spheres and nanobelts of manganese oxide by hydrothermal method and morphology control of them," Chemical Physics Letters, vol. 440, no. 1-3, pp. 134-138, 2007.

[18] X. Wang and Y. Li, "Synthesis and formation mechanism of manganese dioxide nanowires/nanorods," Chemistry, vol. 9, pp. 300-306, 2003.

[19] S. Ching, E. J. Welch, S. M. Hughes, A. B. F. Bahadoor, and S. L. Suib, "Nonaqueous sol-gel syntheses of microporous manganese oxides," Chemistry of Materials, vol. 14, no. 3, pp. 1292-1299, 2002.

[20] N. Wang, X. Cao, L. He et al., "One-Pot synthesis of highly crystallined $\lambda-\mathrm{MnO}_{2}$ nanodisks assembled from nanoparticles: morphology evolutions and phase transitions," The Journal of Physical Chemistry C, vol. 112, no. 2, pp. 365-369, 2008.

[21] Y. Oaki and H. Imai, "One-pot synthesis of manganese oxide nanosheets in aqueous solution: chelation-mediated parallel control of reaction and morphology," Angewandte Chemie, vol. 119, no. 26, pp. 5039-5043, 2007.

[22] X. Yu, Y. He, J. Sun et al., "Nanocrystalline MnO thin film anode for lithium ion batteries with low overpotential," Electrochemical Communications, vol. 11, no. 4, pp. 791-794, 2009.

[23] T. Ahmad, K. V. Ramanujachary, S. E. Lofland, and A. K. Ganguli, "Nanorods of manganese oxalate: a single source precursor to different manganese oxide nanoparticles $(\mathrm{MnO}$, $\left.\mathrm{Mn}_{2} \mathrm{O}_{3}, \mathrm{Mn}_{3} \mathrm{O}_{4}\right)$," Journal of Materials Chemistry, vol. 14, no. 23, pp. 3406-3410, 2004. 
[24] P. Yu, X. Zhang, D. Wang, L. Wang, and Y. Ma, "Shapecontrolled synthesis of 3D hierarchical $\mathrm{MnO}_{2}$ nanostructures for electrochemical supercapacitors," Crystal Growth \& Design, vol. 9, no. 1, pp. 528-533, 2009.

[25] C. Wu, W. Xie, M. Zhang, L. Bai, J. Yang, and Y. Xie, "Environmentally friendly $\gamma-\mathrm{MnO}_{2}$ hexagon-based nanoarchitectures: structural understanding and their energy-saving applications," Chemistry, vol. 15, no. 2, pp. 492-500, 2009.

[26] R. Liu, J. Duay, and S. B. Lee, "Redox exchange induced $\mathrm{MnO}_{2}$ nanoparticle enrichment in poly(3,4-ethylenedioxythiophene) nanowires for electrochemical energy storage," ACS Nano, vol. 4, no. 7, pp. 4299-4307, 2010.

[27] Y. Chen, Y. Hong, Y. Ma, and J. Li, "Synthesis and formation mechanism of urchin-like nano/micro-hybrid $\alpha-\mathrm{MnO}_{2}$," Journal of Alloys and Compounds, vol. 490, pp. 331-335, 2010.

[28] X. Wang and Y. Li, "Selected-control hydrothermal synthesis of $\alpha$ - and $\beta-\mathrm{MnO}_{2}$ single crystal nanowires," Journal of the American Chemical Society, vol. 124, no. 12, pp. 2880-2881, 2002.

[29] N. Kijima, H. Yasuda, T. Sato, and Y. Yoshimura, "Preparation and characterization of open tunnel oxide $\alpha-\mathrm{MnO}_{2}$ precipitated by ozone oxidation," Journal of Solid State Chemistry, vol. 159, no. 1, pp. 94-102, 2001.

[30] M. H. Huang, S. Mao, H. Feick et al., "Room-temperature ultraviolet nanowire nanolasers," Science, vol. 292, no. 5523, pp. 1897-1899, 2001.

[31] S. Chen, J. Zhu, Q. Han, Z. Zheng, Y. Yang, and X. Wang, "Shape-controlled synthesis of one-dimensional $\mathrm{MnO}_{2}$ via a facile quick-precipitation procedure and its electrochemical properties," Crystal Growth \& Design, vol. 9, no. 10, pp. 43564361, 2009.

[32] X. Wang and Y. Li, "Rational synthesis of $\alpha-\mathrm{MnO}_{2}$ single-crystal nanorods," Chemical Communications, no. 7, pp. 764-765, 2002.

[33] D. Zheng, S. Sun, W. Fan et al., "One-step preparation of singlecrystalline $\beta-\mathrm{MnO}_{2}$ nanotubes," Journal of Physical Chemistry $B$, vol. 109, no. 34, pp. 16439-16443, 2005.

[34] H. T. Zhu, J. Luo, H. X. Yang et al., "Birnessite-type $\mathrm{MnO}_{2}$ nanowalls and their magnetic properties," Journal of Physical Chemistry C, vol. 112, no. 44, pp. 17089-17094, 2008.

[35] N. Wang, X. Cao, L. Guo, and S. Yang, “ $\lambda-\mathrm{MnO}_{2}$ nanodisks and their magnetic properties," Nanotechnology, vol. 18, no. 47, Article ID 475605, 2007.

[36] D. Zheng, Z. Yin, W. Zhang, X. Tan, and S. Sun, "Novel branched $\gamma$ - $\mathrm{MnOOH}$ and $\beta-\mathrm{MnO}_{2}$ multipod nanostructures," Crystal Growth \& Design, vol. 6, no. 8, pp. 1733-1735, 2006.

[37] X. Yang, Y. Makita, Z. H. Liu, K. Sakane, and K. Ooi, "Structural characterization of self-assembled $\mathrm{MnO}_{2}$ nanosheets from birnessite manganese oxide single crystals," Chemistry of Materials, vol. 16, no. 26, pp. 5581-5588, 2004.

[38] Z. Li, Y. Ding, Y. Xiong, Q. Yang, and Y. Xie, “One-step solutionbased catalytic route to fabricate novel $\alpha-\mathrm{MnO}_{2}$ hierarchical structures on a large scale," Chemical Communications, no. 7, pp. 918-920, 2005.

[39] J. Fei, Y. Cui, X. Yan et al., "Controlled preparation of $\mathrm{MnO}_{2}$ hierarchical hollow nanostructures and their application in water treatment," Advanced Materials, vol. 20, no. 3, pp. 452456, 2008.

[40] B. Li, G. Rong, Y. Xie, L. Huang, and C. Feng, "Low-temperature synthesis of $\alpha-\mathrm{MnO}_{2}$ hollow urchins and their application in rechargeable $\mathrm{Li}^{+}$batteries," Inorganic Chemistry, vol. 45, no. 16, pp. 6404-6410, 2006.
[41] C. Xia, W. Ning, and G. Lin, "Facile synthesis of novel $\mathrm{MnO}_{2}$ hierarchical nanostructures and their application to nitrite sensing," Sensors and Actuators B, vol. 137, no. 2, pp. 710-714, 2009.

[42] X. Fu, J. Feng, H. Wang, and K. M. Ng, "Room temperature synthesis of a novel $\gamma-\mathrm{MnO}_{2}$ hollow structure for aerobic oxidation of benzyl alcohol," Nanotechnology, vol. 20, no. 37, Article ID 375601, 2009.

[43] X. C. Song, Y. Zhao, and Y. F. Zheng, "Synthesis of $\mathrm{MnO}_{2}$ nanostructures with sea urchin shapes by a sodium dodecyl sulfateassisted hydrothermal process," Crystal Growth \& Design, vol. 7, no. 1, pp. 159-162, 2007.

[44] H. Chen and J. He, "Self-assembly of birnessite manganese dioxide into monodisperse honeycomb and hollow nanospheres," Chemistry Letters, vol. 36, pp. 174-175, 2007.

[45] Q. C. Sun, X. Xu, S. N. Baker, A. D. Christianson, and J. L. Musfeldt, "Experimental determination of ionicity in $\mathrm{MnO}$ nanoparticles," Chemistry of Materials, vol. 23, no. 11, pp. 29562960, 2011.

[46] M. Baldi, E. Finocchio, F. Milella, and G. Busca, "Catalytic combustion of $\mathrm{C} 3$ hydrocarbons and oxygenates over $\mathrm{Mn}_{3} \mathrm{O}_{4}$," Applied Catalysis B, vol. 16, no. 1, pp. 43-51, 1998.

[47] L. Ji and X. Zhang, "Manganese oxide nanoparticle-loaded porous carbon nanofibers as anode materials for highperformance lithium-ion batteries," Electrochemistry Communications, vol. 11, no. 4, pp. 795-798, 2009.

[48] S. L. Brock, M. Sanabria, S. L. Suib, V. Urban, P. Thiyagarajan, and D. I. Potter, "Particle size control and self-assembly processes in novel colloids of nanocrystalline manganese oxide," Journal of Physical Chemistry B, vol. 103, no. 35, pp. 7416-7428, 1999.

[49] Z. Tian, Q. Feng, N. Sumida, Y. Makita, and K. Ooi, "Synthesis of manganese oxide nanofibers by selfassembling hydrothermal process," Chemistry Letters, vol. 33, no. 8, pp. 952-953, 2004.

[50] Y. Oaki and H. Imai, "One-pot synthesis of manganese oxide nanosheets in aqueous solution: chelation-mediated parallel control of reaction and morphology," Angewandte Chemie, vol. 46, pp. 4951-4955, 2007.

[51] Q. Li, J. Wang, Y. He, W. Liu, and X. Qiu, "Growth of nearly monodisperse $\mathrm{MnO}$ nanocrystals in a two-size distribution system," Crystal Growth \& Design, vol. 9, no. 7, pp. 3100-3103, 2009.

[52] M. Yin and S. O'Brien, "Synthesis of monodisperse nanocrystals of manganese oxides," Journal of the American Chemical Society, vol. 125, no. 34, pp. 10180-10181, 2005.

[53] J. Park, E. Kang, C. J. Bae et al., "Synthesis, characterization, and magnetic properties of uniform-sized $\mathrm{MnO}$ nanospheres and nanorods," Journal of Physical Chemistry B, vol. 108, no. 36, pp. 13594-13598, 2004.

[54] A. Puglisi, S. Mondini, S. Cenedese, A. M. Ferretti, N. Santo, and A. Ponti, "Monodisperse octahedral $\alpha$-MnS and $\mathrm{MnO}$ nanoparticles by the decomposition of manganese oleate in the presence of sulfur," Chemistry of Materials, vol. 22, no. 9, pp. 2804-2813, 2010.

[55] S. Xie, X. Zhou, X. Han et al., "Supercrystals from crystallization of octahedral MnO nanocrystals," Journal of Physical Chemistry C, vol. 113, no. 44, pp. 19107-19111, 2009.

[56] R. Xing, G. Liu, Q. Quan et al., "Functional MnO nanoclusters for efficient siRNA delivery," Chemical Communications, vol. 47, pp. 12152-12154, 2011. 
[57] T. Ould-Ely, D. Prieto-Centurion, A. Kumar et al., "Manganese(II) oxide nanohexapods: insight into controlling the form of nanocrystals," Chemistry of Materials, vol. 18, no. 7, pp. 1821-1829, 2006.

[58] I. Rusakova, T. Ould-Ely, C. Hofmann et al., "Nanoparticle shape conservation in the conversion of $\mathrm{MnO}$ nanocrosses into $\mathrm{Mn}_{3} \mathrm{O}_{4}$," Chemistry of Materials, vol. 19, no. 6, pp. 1369-1375, 2007.

[59] X. Li, D. Li, L. Qiao et al., "Interconnected porous $\mathrm{MnO}$ nanoflakes for high-performance lithium ion battery anodes," Journal of Materials Chemistry, vol. 22, pp. 9189-9194, 2012.

[60] H. Ohno, "Making nonmagnetic semiconductors ferromagnetic," Science, vol. 281, no. 5379, pp. 951-956, 1998.

[61] K. M. Nam, Y. Kim, Y. Jo et al., "New crystal structure: synthesis and characterization of hexagonal wurtzite MnO," Journal of the American Chemical Society, vol. 134, pp. 8392-8395, 2012.

[62] X. Zhang, Z. Xing, L. Wang et al., "Synthesis of MnO@C core-shell nanoplates with controllable shell thickness and their electrochemical performance for lithium-ion batteries," Journal of Materials Chemistry, vol. 22, no. 34, pp. 17864-17869, 2012.

[63] T. D. Schladt, K. Koll, S. Prüfer et al., "Multifunctional superparamagnetic $\mathrm{MnO} @ \mathrm{SiO}_{2}$ core/shell nanoparticles and their application for optical and magnetic resonance imaging," Journal of Materials Chemistry, vol. 22, pp. 9253-9262, 2012.

[64] Y. Sun, X. Hu, W. Luo, and Y. Huang, "Porous carbon-modified $\mathrm{MnO}$ disks prepared by a microwave-polyol process and their superior lithium-ion storage properties," Journal of Materials Chemistry, vol. 22, pp. 19190-19195, 2012.

[65] M. Armand and J. M. Tarascon, "Building better batteries," Nature, vol. 451, no. 7179, pp. 652-657, 2008.

[66] X. Sun, X. Wang, L. Qiao et al., "Electrochemical behaviors of porous $\mathrm{SnO}_{2}-\mathrm{Sn} / \mathrm{C}$ composites derived from pyrolysis of $\mathrm{SnO}_{2}$ /poly(vinylidene fluoride)," Electrochimica Acta, vol. 66, pp. 204-209, 2012.

[67] J. Zhao, Z. Tao, J. Liang, and J. Chen, "Facile synthesis of nanoporous $\gamma-\mathrm{MnO}_{2}$ structures and their application in rechargeable li-Ion batteries," Crystal Growth \& Design, vol. 8, pp. 2799-2805, 2008.

[68] K. Zhong, X. Xia, B. Zhang, H. Li, Z. Wang, and L. Chen, "MnO powder as anode active materials for lithium ion batteries," Journal of Power Sources, vol. 195, no. 10, pp. 3300-3308, 2010.

[69] Y. U. Jeong and A. Manthiram, "Nanocrystalline manganese oxides for electrochemical capacitors with neutral electrolytes," Journal of the Electrochemical Society, vol. 149, no. 11, pp. A1419A1422, 2002.

[70] H. Y. Lee and J. B. Goodenough, "Supercapacitor behavior with KCl electrolyte," Journal of Solid State Chemistry, vol. 144, no. 1, pp. 220-223, 1999.

[71] E. Raymundo-Piñero, V. Khomenko, E. Frackowiak, and F. Béguin, "Performance of manganese oxide/CNTs composites as electrode materials for electrochemical capacitors," Journal of the Electrochemical Society, vol. 152, no. 1, pp. A229-A235, 2005.

[72] J. Liu and Q. M. Pan, "MnO/C nanocomposites as high capacity anode materials for li-Ion batteries," Electrochemical and SolidState Letters, vol. 13, no. 10, pp. A139-A142, 2010.

[73] W. Xiao, J. S. Chen, Q. Lu, and X. W. Lou, "Porous spheres assembled from polythiophene (PTh)-coated ultrathin $\mathrm{MnO}_{2}$ nanosheets with enhanced lithium storage capabilities," The Journal of Physical Chemistry C, vol. 114, no. 27, pp. 12048-12051, 2010. 

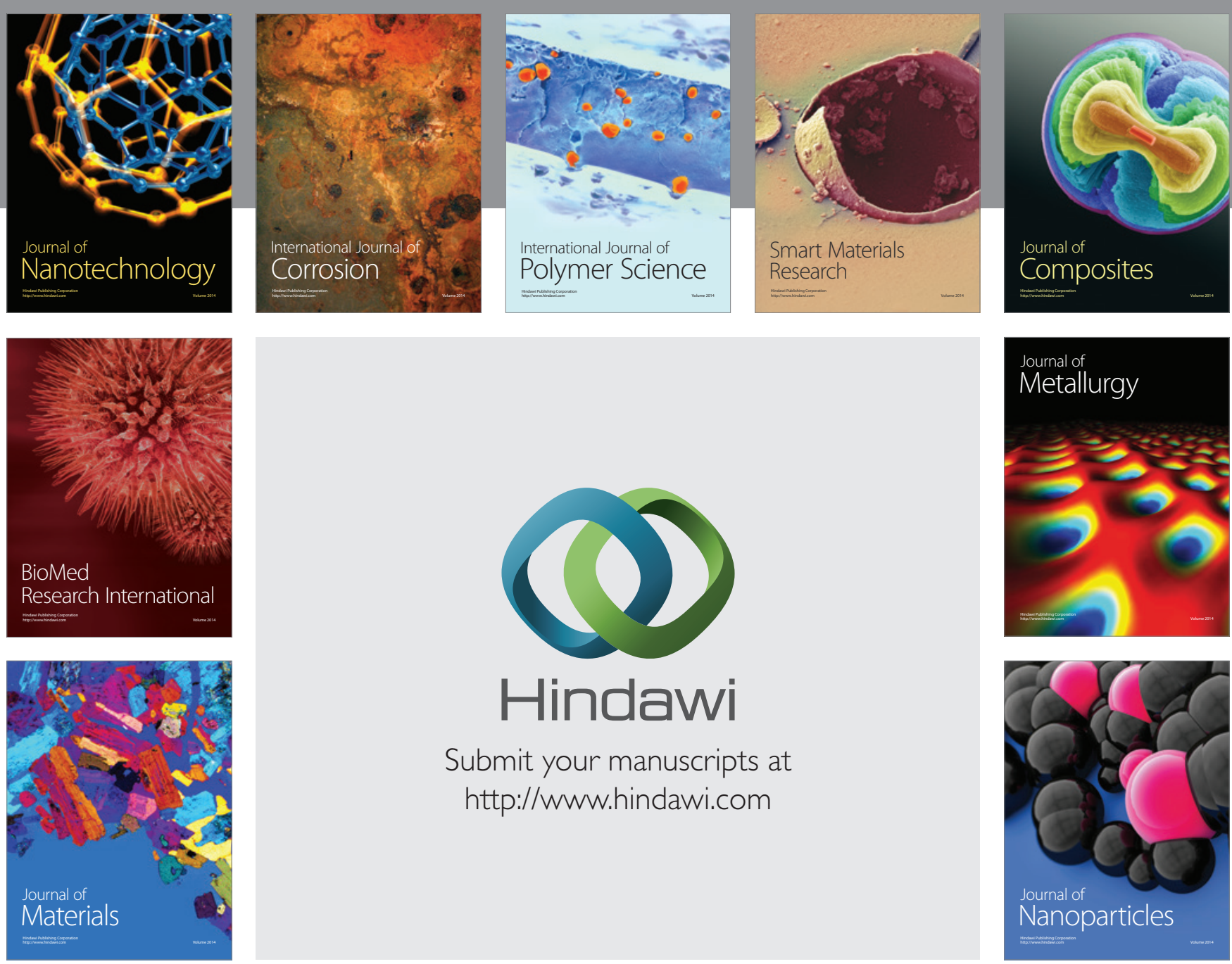

Submit your manuscripts at http://www.hindawi.com
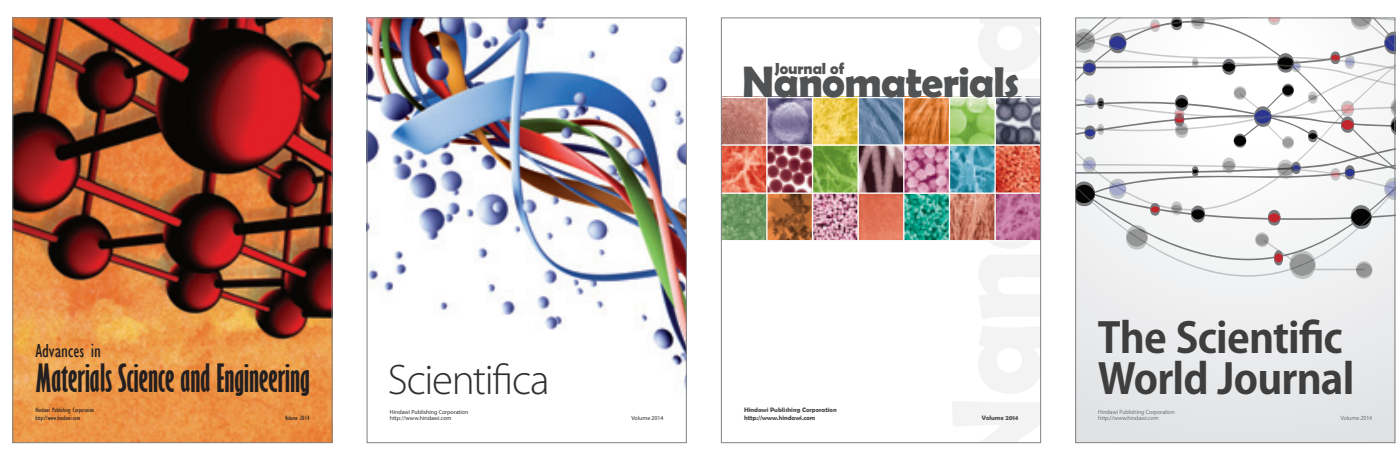

\section{The Scientific World Journal}
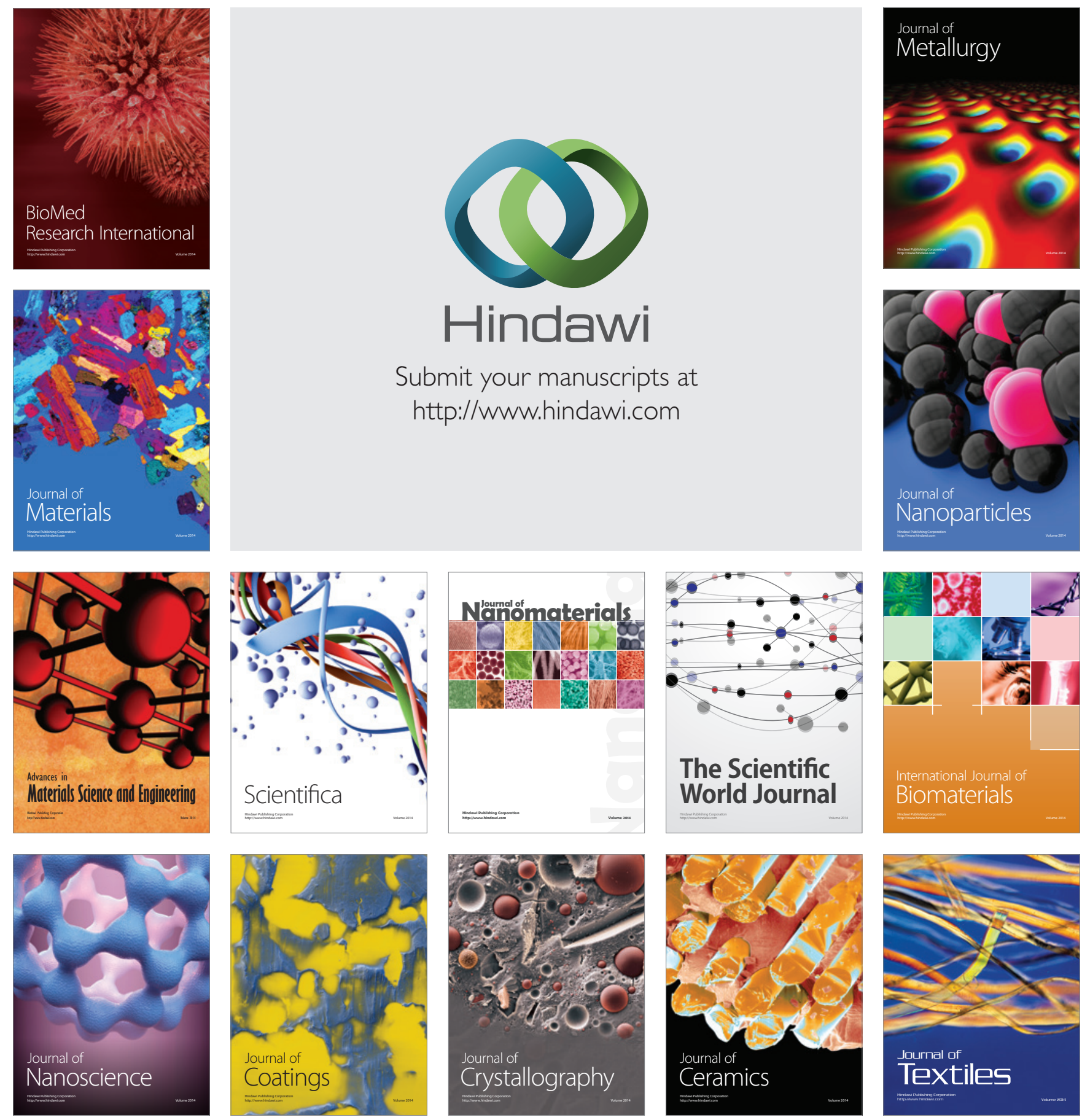